\title{
Projeto parental não compartilhado: implicações no exercício da parentalidade ${ }^{1}$
}

\author{
Sabrina Daiana Cúnico ${ }^{2}$ \\ Pontificia Universidade Católica do Rio Grande do Sul \\ Dorian Mônica Arpini \\ Universidade Federal de Santa Maria
}

\begin{abstract}
RESUMO - Trata-se de uma pesquisa qualitativa, cujo objetivo foi conhecer, a partir do olhar de mulheres chefes de família, o impacto da conjugalidade e do projeto parental não compartilhado no exercício da parentalidade. Participaram deste estudo dez mães que compunham uma família monoparental. Entrevistas semiestruturadas e grupos focais foram utilizados para a coleta de dados, tendo-se realizado uma análise de conteúdo temática. Os resultados evidenciaram que o projeto parental, quando não compartilhado pela dupla parental, produz fragilidades no exercício da parentalidade, em especial no que se refere ao envolvimento paterno. Ademais, identificou-se que, não obstante às mudanças atribuídas ao papel do pai na família, o exercício da paternidade ainda parece ser considerado, na perspectiva das mulheres, como opcional para muitos homens.
\end{abstract}

Palavras-chave: relações conjugais, parentalidade, ausência paterna, relações familiares

\section{A Non-shared Parental Project: The Role of Parenthood and its Implications}

\begin{abstract}
This is a qualitative study, which has as its objective knowing the impact of marital relations and non-shared parental projects on parenting from the perspective of the female head of the household. The participants of this study were ten mothers who constituted monoparental families. Semi-structured interviews and focus groups were used for data collection, and an thematic content analysis was carried out. The results showed that the parental project, when not shared by both parents, produces weak points in the exercise of parenting, especially with regard to the involvement of the fathers. Furthermore, despite the changes attributed to the role of the father in the family, the exercise of fatherhood still seems to be, from the perspective of women, considered as optional for many men.
\end{abstract}

Keywords: marital relations, parenthood, father absence, family relations

Engravidar pode ser resultado de uma série de fatores. Pode ser fruto de uma concepção planejada e almejada pelo casal - o sinal de que o casal quer construir algo junto - ou o resultado de um "acidente" causado pela falha de algum método anticoncepcional ou mesmo pela falta de informação. Pode ser, ainda, decorrência da vontade exclusiva de um ou de outro que passa a não tomar os cuidados necessários para evitar a gravidez (Corso \& Corso, 2011). A definição de uma gravidez não planejada diz respeito a toda gestação que não foi programada pelo casal. Diz-se indesejada quando a gestação vem de encontro aos desejos e expectativas do casal ou inoportuna quando acontece em um momento considerado não favorável (Prietsch, González-Chica, Cesar, \& Mendoza-Sassi, 2011).

Na visão de Pittman (1994), antigamente os casais tinham maior consciência da iminência de serem pais, visto que a gravidez ocorria com o início da vida sexual, que se iniciava com o casamento. Em concordância com esse entendimento, Lopes, Menezes, Santos e Piccinini (2006) pontuam que a forma com que acontece a transição para o casamento parece

1 Este artigo é derivado da dissertação de mestrado da primeira autora, orientada pela segunda, tendo apoio e financiamento da Coordenação de Aperfeiçoamento de Pessoal de Nível Superior (CAPES).

2 Endereço para correspondência: Rua Chile, 461, Apto 503, Porto Alegre, RS, Brasil. CEP: 90.670-140.E-mail: sabrinacunico@yahoo. com.br ter influência direta no planejamento da primeira gravidez, ou seja, a presença de um ritual de casamento pode estar significativamente associada com o planejamento da gravidez do primeiro filho.

Entretanto, em função dos vínculos amorosos contemporâneos, não mais necessariamente sustentados por um matrimônio, o planejamento do número de filhos e do momento de tê-los acabou, para muitos casais, sendo relegado a segundo plano. Isto é, o nascimento dos filhos passa, em muitos casos, a não ser acompanhado por um planejamento familiar do casal (Pittman, 1994).

Essa questão se torna ainda mais complexa na medida em que o número de separações e recomposições conjugais vem aumentando consideravelmente (Pereira \& Arpini, 2012). Entende-se que a ausência de uma decisão compartilhada sobre ter filhos ou ainda um processo de separação conflituoso ou não-consensual podem interferir diretamente no modo com que os pais irão desempenhar a parentalidade pós-dissolução (Corso \& Corso, 2011; Grzybowski \& Wagner, 2010; Turney, 2011). Dessa forma, diversos autores relacionam os altos níveis de ausência paterna a esses fatores, principalmente no que diz respeito ao afastamento do pai de suas responsabilidades parentais após o rompimento do vínculo amoroso do casal (Castillo, 2010; Cúnico \& Arpini, 2013; Eizirik \& Bergmann, 2004).

$\mathrm{O}$ conceito de ausência paterna pode abarcar definições diversas. É possível indicar uma ausência decorrente do 
falecimento do genitor, ausência em função de compromissos de trabalho do pai, ausência após a separação conjugal ${ }^{1}$ ou mesmo afastamento da residência da família em função de encarceramento ou institucionalização (East, Jackson, \& O’Brien, 2006; Sganzerla \& Levandowski, 2010). Neste estudo, esse termo foi utilizado para caracterizar a falta de contato físico e a distância afetiva entre pais e filhos decorrentes da ruptura conjugal.

De acordo com alguns estudos, os homens tendem a recasar-se mais rapidamente do que as mulheres, o que pode indicar uma busca pelo restabelecimento da configuração familiar desfeita (Brito, 2007; Dantas, Jablonski, \& Féres-Carneiro, 2004). Nesse sentido, demarca-se que o recasamento do pai tem potencial para afastá-lo ainda mais do convívio com os filhos provenientes da relação anterior, uma vez que o pai pode acabar se envolvendo mais com o novo casamento e com os possíveis filhos dessa união (Dantas et al., 2004; King \& Heard, 1999). Além disso, Corso e Corso (2011) pontuam que, não raro, muitos pais encaram o seu afastamento da vida dos filhos de relações passadas como sendo uma prova de amor e dedicação para a atual companheira.

A relação estabelecida entre os ex-cônjuges também é apontada como um fator importante que influencia a manutenção da relação parental após a separação. Sendo assim, pais que não possuem um relacionamento amigável com a ex-companheira e/ou a família desta, podem acabar por se distanciar também dos filhos provenientes dessa relação (Brito, 2007; Cúnico \& Arpini, 2013; Fonseca, 2005). Em outros termos, manter-se longe do ex-cônjuge se torna uma prioridade, acima de ficar perto dos filhos (Corso \& Corso, 2011).

Nesse ensejo, faz-se necessário compreender a influência do comportamento materno na ausência do pai. Entende-se que os efeitos do afastamento paterno sobre a criança serão, em vários casos, mediados pela interação da mãe com os filhos (Eizirik \& Bergmann, 2004). Se um por lado a mãe pode atuar como mediadora da relação pai-filhos, de outro, ela pode se converter em obstáculo para que essa relação se consolide (Gomes \& Resende, 2004).

Nesse contexto, algumas mães podem apresentar dificuldades em desvincular-se dos conflitos referentes ao relacionamento conjugal, deslocando-os para a relação parental e dificultando, assim, o contato entre pais e filhos (Dantas et al., 2004; Padilha, 2008; Pereira, 2011). Dessa forma, entende-se que a satisfação materna em relação ao ex-companheiro após a separação deve ser entendida como um elemento crucial que poderá interferir na adaptação do filho a essa nova situação, ou seja, mães insatisfeitas e infelizes podem acabar por transmitir esses sentimentos aos filhos (King \& Heard, 1999).

A partir da experiência da separação, podem ocorrer diferentes respostas e reações por parte dos pais, as quais podem ser influenciadas por vários fatores (Hack \& Ramires, 2010). Autores como Housel (2004) e Borsa e Nunes (2011)

1 Neste estudo, o termo separação conjugal foi empregado para caracterizar qualquer dissolução do vínculo entre um casal, não se limitando àquelas relações que são formalizadas por lei. têm destacado a importância do exercício da parentalidade e de seus desdobramentos nas relações familiares, evidenciando a contribuição e relevância do pai e da mãe para os cuidados com os filhos. Há o entendimento de que tanto o pai quanto a mãe são fundamentais aos filhos e que a continuidade do exercício parental após o divórcio é muito importante para a manutenção dos vínculos (Veludo \& Viana, 2012). Assim, é no cotidiano de cada contexto familiar que devem se dar as mudanças e adaptações necessárias ao pleno exercício da coparentalidade, esta entendida como um interjogo de papeis que se relacionam com o cuidado global da criança, incluindo valores, ideais e expectativas dirigidas aos filhos, em um exercício de responsabilidade conjunta (Grzybowski \& Wagner, 2010).

Contudo, embora venha se destacando a compreensão da importância da coparentalidade, e de um maior envolvimento dos homens nos cuidados com os filhos, ainda persiste no senso comum uma idealização da maternidade, diferentemente da paternidade, A atuação paterna junto aos filhos, relacionada à atenção e a estar presente na vida deles, ainda é vista como opcional ou complementar à ação materna (Cúnico \& Arpini, 2013; Staudt \& Wagner, 2008).

Sendo assim, além de as próprias mães reforçarem e perpetuarem o mito do amor materno, não é incomum que muitos pais também partilhem da crença de que os filhos não possam ficar sem os cuidados da mãe, por serem elas mais preparadas para desempenhar essa função (Padilha, 2008; Staudt \& Wagner, 2008). Demarcadas essas questões e assumindo a problemática decorrente da teia de relações que se estabelecem após o fim do relacionamento do casal, este estudo tem por objetivo conhecer, a partir do olhar de mulheres chefes de família, o impacto da conjugalidade e do projeto parental não compartilhado no exercício da parentalidade.

\section{Método}

\section{Delineamento}

Trata-se de um estudo exploratório e descritivo (Gil, 2002), com abordagem qualitativa. Para Creswell (2010), uma abordagem qualitativa geralmente é realizada quando o pesquisador entende que, para o fenômeno ou conceito estudado, existirão diversas e variadas significações e representações.

\section{Participantes}

Integraram este estudo 10 mães que detêm a guarda dos filhos, sem parceiros em situação de coabitação e residentes em uma cidade do interior do Rio Grande do Sul. As mulheres foram selecionadas por conveniência, tendo sido identificadas a partir de consulta ao cadastro do Centro de Referência de Assistência Social (CRAS) da cidade em que a pesquisa foi realizada. Não houve qualquer restrição em 
relação ao estado civil das participantes, bastando que não residissem com o pai do(s) filho(s) ou outro companheiro. O número de participantes seguiu o critério de saturação, o qual é definido por Turato (2008) como o momento em que novas falas passam a ter acréscimos pouco significativos em vista dos objetivos inicialmente propostos pela pesquisa.

As participantes tinham entre 22 e 49 anos, sendo sete delas solteiras, uma separada e duas divorciadas. Apenas uma das entrevistadas possuía outro relacionamento no momento da sua participação nesta pesquisa. $\mathrm{O}$ número de filhos variou de um a seis, com idades entre um a 28 anos. Todas as mulheres coabitavam com pelo menos um dos filhos no momento em que a pesquisa foi conduzida.

\section{Instrumentos e Procedimentos}

Optou-se pela coleta de dados a partir de entrevista semiestruturada e de grupo focal. A entrevista foi utilizada como instrumento na medida em que se entende que seu emprego, no contexto da pesquisa qualitativa, auxilia a explorar em profundidade os pontos de vista dos entrevistados (Gaskell, 2005). Os tópicos abordados nas entrevistas foram os seguintes: (a) Experiência com o final da relação conjugal; (b) Vivência acerca da paternidade antes e depois da relação conjugal desfeita; (c) Transmissão da ausência paterna aos filhos e (d) Lugar atribuído ao pai na família.

A utilização de grupos focais se deu em função da expectativa de que, no grupo, por meio da possibilidade de troca e da circulação das experiências vivenciadas pelas mães, elementos que, por ventura, pudessem não ter se revelado nas entrevistas viessem à tona nesse momento. Seu objetivo consiste em estimular os participantes a falar e a reagir àquilo que outras pessoas no grupo dizem, em vez de somente interagir com o pesquisador (Barbour, 2009; Gaskell, 2005).

As participantes foram contatadas por telefone, sendo que todas foram informadas desde o primeiro contato sobre os objetivos do estudo, bem como sobre a forma de coleta e análise dos dados. Mediante consentimento verbal e assinatura do Termo de Consentimento Livre e Esclarecido, foram realizadas as entrevistas com dez mães. Todas elas aconteceram nas dependências do CRAS, tendo sido gravadas e transcritas literalmente para posterior análise. Depois de finalizada essa etapa, as participantes foram convidadas a participarem de um segundo momento da pesquisa, envolvendo os grupos focais. Seis compareceram aos encontros. Sendo assim, foram realizados dois grupos contendo três mães em cada um deles.

Salienta-se que os grupos tiveram por disparador duas situações problemas, as quais foram elaboradas após análise das transcrições das entrevistas individuais. As situações problemas foram assim definidas: Situação 1: Paula e João foram casados durante 08 anos e possuem dois filhos, Tiago tem 7 anos e Pedro 4 anos. Durante o tempo em que viveram juntos, o casal manteve uma boa comunicação entre si a respeito das responsabilidades com os filhos. João era um pai muito presente e preocupado com a educação deles. No entanto, isso começou a mudar a partir do momento em que Paula e João se separaram. A separação aconteceu há cerca de um ano e Paula percebe que João se afasta cada dia mais do convívio com as crianças. Tiago, o mais velho, pergunta insistentemente para a mãe por que o pai não lhe visita mais. $\mathrm{Na}$ última semana, João ligou para Tiago dizendo que ia buscá-lo para passear, mas não apareceu. Não foi a primeira vez que João não compareceu a um encontro marcado com os filhos.

Situação 2: Luisa e Bruno namoravam há 02 meses quando ela decidiu que era o momento de eles terem um filho. Três meses depois, o relacionamento de Luisa e Bruno terminou e ele se afastou totalmente da ex-companheira, que já estava esperando um filho seu. Bruno não acompanhou a gestação nem o nascimento da menina, que se chamava Luana. Bruno e Luisa não conseguiram manter uma relação amigável mesmo depois do nascimento da filha, a qual ele demorou para conhecer, pois se recusava a ir à casa de Luisa visitá-la. Luana hoje tem 03 anos e poucas vezes viu o pai. Assim como as entrevistas, os dois grupos foram gravados e transcritos na íntegra.

\section{Análise de Dados}

Neste estudo, optou-se por analisar as informações coletadas a partir da Análise de Conteúdo Temática, que tem por conceito central o tema. "O tema é a unidade de significação que se liberta naturalmente de um texto analisado segundo certos critérios relativos à teoria que serve de guia à leitura" (Bardin, 2011, p. 135).

Inicialmente, realizou-se a leitura individual de cada entrevista transcrita. Esse procedimento foi realizado de forma individual por dois pesquisadores, que, após a primeira leitura detalhada, compartilharam suas impressões e procedeu-se o momento de análise. A etapa seguinte consistiu na análise do conjunto do material obtido nas entrevistas, a partir dos quais foram elaboradas as situações problemas cuja utilização se deu nos grupos focais. Após, realizou-se a análise do material transcrito dos grupos. Por fim, analisouse o material produzido nas entrevistas e nos grupos focais em sua totalidade. A partir dessa análise, emergiram as categorias de análise.

\section{Considerações Éticas}

Salienta-se que o projeto de pesquisa que culminou neste trabalho foi realizado conforme as recomendações das Diretrizes e Normas Regulamentadoras de Pesquisa Envolvendo Seres Humanos (Resolução 466/12 do Conselho Nacional de Saúde). O desenvolvimento da pesquisa apenas aconteceu após a sua aprovação pelo comitê de ética da instituição à qual as autoras estão vinculadas, tendo sido o projeto aprovado sob o número CAAE 05021912.7.0000.5346. Com o intuito de preservar o anonimato das participantes, as falas ilustrativas das categorias serão apresentadas pela letra $\mathrm{M}$ (mãe), seguida do número que representa a ordem da realização das entrevistas, sendo diferenciadas pelas letras E (entrevista) e G (grupo). 


\section{Resultados e discussão}

\section{“Achei que era Época de eu Ter e eu Tive, Sabe?": A Ausência do Projeto Parental pelo Casal}

A decisão de ter um filho envolve, frequentemente, uma série de questões. No que tange às participantes deste estudo, os relatos indicaram que a gestação foi uma decisão delas próprias, ou seja, não foi acompanhada por um projeto conjunto do casal. "Eu, na verdade, eu queria uma gravidez independente, independente se ele assumisse ou não. (...) Eu decidi ter o meu filho, entende? Eu escolhi ele como pai do meu filho" (M1-E); "Do pai das minhas filhas tava péssimo [a relação do casal], né! Mas mesmo assim eu quis engravidar (...) eu não pensava muito no... no trabalho, na dificuldade de criar um filho. Eu não tinha muita noção, nem pensava direito, eu queria ter uma filha" (M9-E).

A literatura que discorre sobre o tema sugere que o momento ou o modo como a gestação se deu parece ter influência direta na forma com que os pais - em especial aqueles que não se sentiram incluídos no projeto da parentalidade - vão se posicionar frente aos filhos (Corso \& Corso, 2011; Fonseca, 2005; Grzybowski \& Wagner, 2010). No caso das participantes deste estudo, a reação foi o afastamento.

Achei que era época de eu ter e eu tive, sabe? Só que dai ele se afastou, tanto é que a gravidez eu tive sozinha, sabe, ele não teve nenhum acompanhamento durante a minha gestação e nem a mãe [dele] sabia, nem os pais dele sabiam, aí.. mas eu me achava assim no direito de... de ter o meu filho sozinha, sabe? (M1-G)

Em contrapartida, outras mães foram categóricas ao mencionarem sua esperança de que o nascimento do filho resgatasse o relacionamento amoroso que já havia terminado. "É aquilo... eu passei a gestação sozinha, não tinha contato com ele [com o pai do filho], mas aquela minha expectativa: a hora que nascesse a criança a gente podia se reaproximar e não foi" (M4-E).

Houve essa aproximação deles [da família do pai da criança] de me conhecerem, de conhecerem o João recém nascido [filho] (...) Mas só que eu queria mais que isso, eu tava naquela fase que eu queria ficar com ele, com o pai e eu pensei "ah, agora é a oportunidade", só que já era tarde também pra nós. Ele já tava com outra, mas eu tentava daqui e dali, mas não, não adiantou, não teve jeito. (M4-E)

A partir da análise dos recortes apresentados, pode-se pensar que o filho veio para ser um dos principais pontos de sustentação dessa relação, o que não aconteceu. Tachibana, Santos e Duarte (2006), em estudo realizado com gestantes a respeito da gravidez não planejada, evidenciaram que, em muitos casos, a gravidez irrompeu como uma tentativa de reconstruir os relacionamentos amorosos fadados ao término. Resultados similares foram encontrados em outros estudos (Grzybowski \& Wagner, 2010; Turney, 2011), que identificaram correlações entre a manutenção da relação parental pós-separação e o modo como o filho "surgiu" na relação do casal. Assim, quando a gravidez era inesperada e os pais avaliavam que a mãe engravidou deliberadamente, havia dificuldades, por parte dos pais, de vinculação com a criança. Esse entendimento também foi explicitado por uma das participantes do presente estudo:

Vamos pensar aqui como homem... primeira coisa que homem pensa quando... principalmente quando acontece assim, do relacionamento já não tá mais assim tão amigável e dai a mulher fica grávida, a primeira coisa que eles dizem "ah, é pra manter o relacionamento, por interesse”, né? (M10-G)

Essa atitude de culpabilizar aquele genitor - neste caso, a mãe - que desejou ter o filho sem o consentimento do companheiro também esteve presente no discurso das participantes deste estudo no momento em que debateram sobre uma das situações problemas que alimentaram o grupo focal. Tal situação relatava a história de Luisa e Bruno, os quais namoravam há 02 meses quando ela decidiu que era o momento de eles terem um filho. Três meses depois, o relacionamento de Luisa e Bruno terminou e ele se afastou totalmente da ex-companheira, que já estava esperando um filho seu. Ao serem questionadas sobre os motivos que levaram Bruno a se afastar, as mães responderam:

Porque ela decidiu ter filho, não ele, ela não chegou e perguntou pra ele "Ó, Bruno, vamo ter um filho, tu quer ter filho comigo?", ela simplesmente disse pra ele "vamo ter um filho", pronto! (...) Ela que abriu a guarda, ela que fez, então... ela que tem que aguentar, né? (M2-G)

Porque ali o que que aconteceu? Ambos pensaram em si, não pensaram na criança, né, pelo que vê da historia, né, pensaram em si, "ah, eu vou ter minha filha sozinha, se ele não procurar problema édele", mas e mais adiante? Será que não pensaram que a criança pode sofrer né, a criança vai arcar com tudo aquilo que eles fizeram no passado, né? (M10-G)

O recorte anterior oferece uma contribuição interessante para essa problemática ao questionar o lugar que o filho passa a ter na vida dos pais. A respeito disso, Szejer e Stewart (1997) pontuam que, em muitos casos, os filhos que nascem de uma relação em vias de dissolução carregam o peso de uma missão reparadora, independentemente se conseguem ou não cumprir esta tarefa.

Também interessa destacar que algumas mães, ao analisarem a situação problema trabalhada no grupo focal, ressaltaram a importância de pensar a decisão da gestação a partir da perspectiva do filho. No entanto, em seus relatos sobre a sua própria experiência - tal como apresentado anteriormente -, essa reflexão não se fez presente, uma vez que refeririam ter decidido elas mesmas que queriam ser mães, embora correndo o risco de não contarem com a aceitação da gravidez por parte do pai. Evidentemente, este estudo não objetiva culpabilizar a mãe pelos casos de gravidez que não foi planejada pelo casal. Na realidade, objetiva menos ainda tentar identificar um "culpado" pelo acontecimento, mas evidenciar a importância de que a decisão por ter um filho faça parte de um projeto de vida que leve em consideração todos os desafios e as responsabilidades que estão implicadas nessa decisão.

\section{“Ele Nunca Foi Fiel, né?": A Instabilidade das Relações Conjugais}

É sabido que a família contemporânea não é mais sustentada, essencialmente, por um casamento. $\mathrm{Na}$ 
perspectiva atual, o rompimento das relações amorosas se dá no momento em que o afeto, o companheirismo e/ ou os objetivos em comum já não mais existam (Spengler, 2012; Turney, 2011). Entretanto, quando o casal tem filhos, a questão se complexifica, uma vez que os filhos seguirão necessitando de cuidados, atenção e carinho (Corso \& Corso, 2011; Grzybowski \& Wagner, 2010).

Dito isso, pode-se pensar que a decisão de ter um filho esteja relacionada a um momento de estabilidade no relacionamento do casal, que passa a considerar os prós e contras dessa decisão (Matias, Silva, \& Fontaine, 2011). No entanto, neste estudo, a questão que se apresentou de forma contundente foi a evidência de relacionamentos instáveis de casais que, antes mesmo de consolidar qualquer tipo de projeto ou sonho em comum, tornaram-se pai e mãe.

A relação assim foi um namoro bem curto, né, e a gente já estava não se acertando, então quando eu resolvi terminar, que não tava dando certo, eu já estava grávida, né, foi bem pouco tempo, não sei se chegou a uns 3, 4 meses e ai eu engravidei. (M8-E) $E$ do Tiago [segundo filho, de uma segunda relação] também não foi muito tempo, acho que foi uns 4, 5 meses, sabe, e aí eu pensei que ia dar certo, que eu ia gostar, mas aí acabei não gostando, dai eu disse "eu não posso ficar forçando um relacionamento que não tá legal”, dai a gente terminou, só que ai eu já tava grávida. (M8-E)

Nesse contexto de instabilidade conjugal, não são raros os casos em que processos de reconhecimento de paternidade são movidos, seja pelo meio jurídico ou por meio da busca pelo genitor para que ele assuma seus compromissos de pai (Corso \& Corso, 2011; Fonseca, 2005). Muitos homens parecem encarar a chegada do filho fruto de um relacionamento não estável ou de uma parceira ocasional como um fardo cujo peso não estão dispostos a carregar, afastando-se totalmente do convívio com os mesmos (Corso \& Corso, 2011; Turney, 2011).

Um filho geralmente implica mudanças nas rotinas, maiores responsabilidades, bem como diminuição do tempo do casal um para o outro, uma vez que os cônjuges passam a exercer novos papéis de pai e de mãe (Matias et al., 2011). Considerando que o relacionamento do casal não estava em um bom momento e que, ainda assim, essas mulheres desejaram gerar um filho a partir dessa relação, pode-se pensar que houve, de certa forma, uma busca por parte das mães de, por meio do pai, resgatar o marido. Ou seja, parece ter havido uma expectativa de que os problemas no relacionamento estariam resolvidos a partir do nascimento de uma criança.

Ah, pra te dizer a verdade, desde que nós namoramos assim ele nunca foi fiel, né, depois de um mês de casado, ele foi chamado pelo conselho tutelar pra reconhecer um filho que ele tinha feito durante o namoro (...) Ai depois de tanto ele pedir, depois de 5 cinco anos, que ele pedia filho, eu tentei fazer uma filha com ele. Só que com 6 meses de gravidez ele me traiu, me largou e ficou com outra que ele tinha conhecido duas semanas antes (...) ele queria tanto um filho, que eu pensei que ele ia ser um pai decente, né, pelo menos com a filha, né, mas não foi o que aconteceu. (M2-E)
Seguindo nessa discussão, a fala seguinte traz um aspecto interessante que merece ser destacado. De acordo com o relato da participante (M9), a sua decisão de engravidar foi motivada não só pelo desejo do seu ex-companheiro em tornar-se pai, mas também pelo seu próprio desejo de encontrar alguém com quem dividir o cuidado e as responsabilidades com as filhas mais velhas, fruto de outra relação já desfeita. Assim, pode-se pensar que esse filho foi concebido a partir de uma relação de "troca": o excompanheiro teria um filho, como era a sua vontade, e a mãe teria alguém para lhe ajudar a cuidar das suas primogênitas.

Ele queria um filho pra cuidar, porque o outro ele não pôde cuidar, né? [o outro filho morava com a mãe] Daí eu concordei! Eu queria também, né? Quando eu conheci ele, eu achei que eu precisava de alguém pra me ajudar a criar as minhas filhas, né? [filhas de outro relacionamento] Tipo, foi um... uma ajuda que eu achei que ia ser, né? (...) Daí, tipo, no mesmo dia que eu dei a notícia que eu tava grávida, ele foi pra rua e voltou no outro dia de manhã... meio-dia, né? (M9-E)

Diante das histórias apresentadas, pôde-se perceber que se tratava, em geral, de histórias de filhos frutos de relações instáveis, em que, embora a ocorrência da gestação tenha se dado por motivos diversos - ausência de projeto parental pelo casal, "descuido", vontade do ex-companheiro em ser pai, desejo em compartilhar o cuidado dos filhos -, nenhum dos motivos foi forte o suficiente para manter as relações de parentalidade após a dissolução do relacionamento do casal. É nesse sentido que Corso e Corso (2011) pontuam que, ao mesmo tempo em que engravidar pode ser fruto de uma concepção buscada pelo casal, pode ser também o "início de uma seqüência de abandonos masculinos, nos quais a mulher sempre se encontra enfim só, criando o filho e ruminando seus sonhos frustrados de família feliz" (p. 52). Tais considerações reforçam a ideia já amplamente discutida nesta categoria da importância da gestação fazer parte de um projeto compartilhado pelo casal.

\section{"Ele Não Veio Mais Ver os Filhos": O Afastamento Paterno após o Fim do Relacionamento do Casal}

Em razão de as mães participantes do estudo estarem na condição de chefes da família, ou seja, em um contexto de monoparentalidade, a ausência paterna foi uma das principais questões que permearam o discurso da maioria das participantes deste estudo. As mães relataram não contar com o apoio do pai de seus filhos, o qual teria se afastado totalmente do convívio com a criança após a dissolução do relacionamento amoroso.

Ah, agora ele tá muito mais distante... ele ficou um ano sem procurar o Mateus [filho], assim, sem pegar o Mateus para sair, sabe? Quando nós nos separamos...que ele foi morar lá fora, geralmente ele vinha pela parte da manhã, quando o Mateus tava na escola, sabe? Final de semana ele não pegava, ele não vinha, ele não procurava, pouco ligava, sabe? (M1-E)

Se ele gostasse dos filhos mesmo, quisesse o bem-estar delas, ele taria com elas hoje, né, ele tem direito a ter final de semanas com elas (...) mas não sabe nem se tão morta, se tão viva, se tão gorda, magra, se tão doente, se tão sã, nada, nada.... as 
atividades que elas fazem no dia-a-dia ele não sabe? Entende aquele pai que faz e tchau? É a mesma coisa. Elas precisam muito do carinho dele, da atenção dele, ele não dá...faz quase 3 anos que não vê elas. (M2-E)

Tais considerações evidenciam a preocupação já sinalizada por diversos estudos que demonstram que não são raros os casos de pais que reduzem o convívio com os filhos provenientes da relação conjugal desfeita, afastandose, sobretudo, afetivamente destes (Corso \& Corso, 2011; Cúnico \& Arpini, 2013; King \& Heard, 1999). Nesse sentido, embora alguns homens assumam de fato seus compromissos de pai desde os primeiros momentos da vida do bebê, refletese o quanto essa participação ainda parece ser vista como opcional para muitos deles (Turney, 2011). Isto é, aqueles pais que não desejam se engajar nesse cuidado, autorizam-se ao afastamento: "Nós três vivemos sozinhas e é só nós, ele não entra no meio...porque ele não ajuda, ele não participa, ele não quer participar" (M2-E); "Ele não pôde, ou não quis na verdade, fazer parte da nossa família e nem do papel [de pai]" (M4-E).

Inúmeras podem ser as razões que levam os pais a abdicarem do exercício da paternidade ao final da relação conjugal: a má relação com a ex-companheira e/ou a família desta, novos relacionamentos do pai ou da mãe, além das questões já discutidas a respeito da falta de projeto parental pelo casal (Cúnico \& Arpini, 2013). Pode-se também considerar a relutância que alguns pais possuem em aceitar o fim do relacionamento amoroso como sendo uma das causas para uma futura ausência paterna.

Essa situação pode fazer com que alguns pais tenham dificuldades em compreender que quem se separa é o casal conjugal, devendo a relação parental se manter (Corso \& Corso, 2011; Pereira, 2011). Nesse contexto, entende-se que o distanciamento do pai pode ser um desdobramento importante dos ressentimentos que atravessam esses relacionamentos desfeitos (Reis, 2010).

Logo no início ele não aceitou a separação, sabe, ele se isolou das gurias, né, excluiu elas, elas sentiram bastante, né, a falta do pai. Eu acho que ele usou os filhos de arma né, como quem diz "ah, pra mim dar atenção pros filhos, ela vai ter que voltar", sabe, ele quis fazer um jogo usando as filhas, né? (M10-E)

Vale lembrar que, nos casos em que há um distanciamento do pai, há, frequentemente, mudanças nas relações das crianças com a família extensa paterna, isto é, avós, tios, primos, entre outros. Esse decréscimo de convívio pode ser explicado pela própria situação da separação, já que a família do pai pode ser vista como uma extensão da relação paterna. Prejudicada essa relação, aquela acaba sendo também dificultada (Brito, 2007; Padilha, 2008; Reis, 2010).

Cabe destacar, no entanto, que da mesma forma que atualmente a ideia de família é referida a partir de sua pluralidade, entendimento semelhante deveria acompanhar a estrutura familiar após a separação conjugal. Isso significa que não há um padrão obrigatório de relacionamento estabelecido após o rompimento do casal (Brito, 2007). Assim, embora o distanciamento do pai possa ser considerado uma importante consequência da separação, não seria correto afirmar que essa atitude corresponda a totalidade dos pais separados.

\section{"Não Adianta Esconder, Tem que Falar a Verdade": A Mãe no Contexto da Ausência Paterna}

Embora haja, atualmente, um número expressivo de separações, entende-se que a ruptura conjugal não deva ser reduzida a uma situação corriqueira, à qual os filhos simplesmente se acostumam. Ao contrário, nem sempre a separação será vista por eles como a melhor solução para os desentendimentos entre os pais (Brito, 2007; Wallerstein $\&$ Kelly, 1998). No que tange às participantes deste estudo, os relatos indicaram que os filhos as culparam pelo fim do relacionamento e pelo consequente afastamento do pai: "Logo que ele foi embora, ela botava a culpa em mim, que o pai dela tinha saído de casa por minha culpa, sabe? Ela me olhava assim com uma revolta, sabe, no olhar" (M2-E); "Quando eu me separei, ela disse um dia chorando pra mim 'porque que tu brigava tanto com meu pai?' e eu nem brigava, né, então, quer dizer, eles tem aquela necessidade de explicação, não adianta" (M3-G).

$\mathrm{O}$ recorte anterior traz um aspecto importante que merece ser destacado. A participante M3 pontua que os filhos possuem uma necessidade de compreender os motivos que levaram à separação dos pais. Nem sempre a ruptura conjugal é precedida por brigas sérias entre os cônjuges na frente dos filhos, o que pode tornar a ideia da separação ainda mais difícil de ser compreendida (Brito, 2007; Wallerstein \& Kelly, 1998). Além disso, em muitas situações - tais quais as apresentadas pelas mães deste estudo -, o pai nem sequer chegou a morar junto com os filhos, o que também pode gerar questionamentos a respeito dessa ausência.

Sobre esse aspecto, Ferrari (2007) afirma que as crianças possuem, efetivamente, necessidade de entender por que o pai se afastou do convívio da família - ou por que nunca esteve presente - e de escutar as razões para o afastamento do próprio pai e não a partir da interpretação da mãe. Porém, frequentemente, em decorrência do distanciamento paterno, serão as mães que precisarão dar conta dessa demanda de explicação dos filhos (Dolto, 1989/2011). Para as entrevistadas, é necessário, sobretudo, dizer a verdade.

Não adianta esconder, tem que falar a verdade, é o que eu digo pras minhas filhas... eu digo pra elas "olha minhas filhas, a mãe que carregou vocês 9 meses, né, a mãe que deu mamá, que trocou fralda, leva vocês no médico até hoje, corre com vocês pra médico, pra conseguir psicólogo, vai na escola, nas reunião, né, tudo, então vocês tem que aceitar a mãe que tá aqui com vocês" (M2-G)

É dificil, né, tu explicar pra uma criança que ela tem o pai e o pai não procura, né, mas tu também esconder tudo tu não pode, né, porque dai ela vai ver que os coleguinhas delas têm os pais, tu vai dizer o quê? Que o papai do céu levou? Tu não vai poder mentir, porque mais adiante quem sabe esse pai apareça, né? (M10-G)

Observou-se, nos discursos das mulheres entrevistadas, certa homogeneidade enunciativa no que se refere ao posicionamento materno frente à ausência do pai. As mães pareceram ter uma preocupação evidente em se posicionar de modo que, futuramente, os filhos reconheçam que o distanciamento paterno não foi motivado por uma imposição da mãe, mas por uma escolha própria do pai. 
Eles [pais] prometem e não aparecem, dai pegava aquela fase, a criança chorava "porque meu papai", dai eu sempre sentava com ela e dizia "Luisa, não deu pra ele vim, quem sabe o papai tá trabalhando, né”, sabendo que não era aquilo, né, mas como é que eu vou dizer pra criança "ó, teu pai não quis vim porque não quer te ver, né?" (...) é complicado pra gente, porque no fim a gente não quer mostrar quem eles realmente são, né, que, com o tempo, eles vão começar a ver, né, vão crescer, vão ver que o pai isolou eles, vão ver que o pai não ajudou. (M10-G) Ao discorrerem sobre o impacto que tal afastamento possui na vida das crianças, as participantes foram unânimes em afirmar que a ausência do pai é fonte de sofrimento para os filhos (Wallerstein \& Kelly, 1998). Ao depararem-se com essa realidade, as mães relataram sentimentos de revolta e também de culpa, uma vez que eram elas que precisavam mediar os efeitos dessa ausência (Eizirik \& Bergmann, 2004; King \& Heard, 1999).

Chega época do dia dos pais, né, é triste até, né, vou eu no lugar do pai lá, só eu de mãe, dai ela sempre se questiona, né, porque que o pai dela não vai (...) Assim, como mãe, quando a gente passa por isso é uma revolta grande, né, com a gente mesmo, né, porque dai a gente pensa assim "como é que eu fui capaz de botar no mundo com essa criatura", porque a gente se sente culpada, né? (M10-G)

A Tatiana [filha] qualquer propaganda que tenha pai e filho, ela chora, sabe, ela se admira ver um pai brincando com os filho, sabe? As vezes, nós tamo passando na rua e tem um pai brincando com um filho, com uma filha, ela fica admirada olhando, porque ela não tem aquilo ali e eu me culpo muito assim pelo fato de não ter conseguido escolher um pai pra elas, né, porque é difícil a gente achar um marido e um pai ao mesmo tempo, é bem difícil [fica emocionada]. (M2-E)

Ademais, também se identificou que algumas mães se mostraram incomodadas com a repercussão que o afastamento do pai tinha na vida dos filhos, visto que se sentiam, de certa maneira, preteridas em comparação com os pais. O recorte a seguir ilustra esta afirmação:

Porque, às vezes, tu cansa, realmente tu cansa, tu trabalha o dia todo, tinha aquele compromisso de largar na creche, inverno, verão, na chuva, sabe, dai tu chegava em casa, escutava choro "porque meu pai..." (...) eu também já tava me sufocando, né, tava começando a me estressar com aquilo ali, dai...porque as vezes tu pensa né, "ah, porque que choram pelo pai e por mim não choram? (M10-E)

A despeito das adversidades decorrentes do afastamento do pai, evidenciou-se que as mães parecem lidar com as questões que envolvem os sentimentos das crianças frente à ausência paterna por meio de uma relação de proximidade e diálogo, não desqualificando o pai ausente para os filhos. Tal situação parece indicar uma clareza por parte dessas mães a respeito da importância de não deslocar os possíveis conflitos decorrentes do relacionamento conjugal para a relação parental (Dolto 1989/2011; Pereira, 2011; Warpechowski \& Mosmann, 2012).

Em contrapartida, embora se queixando do afastamento paterno, algumas mães afirmaram que não faziam verdadeiramente questão de que esse pai fosse presente e participativo na vida dos filhos. Tal afirmação encontra correlação com resultados de outros estudos que afirmam que, de fato, muitas mães veem pouco valor no envolvimento entre pai e filho (Dantas et al., 2004; King \& Heard, 1999; Wallerstein \& Kelly, 1998): "Prefiro assim... [pai não sendo muito presente] prefiro assim, porque ele tem um pensamento completamente diferente do meu hoje, né, então...eu consegui colocar tudo do jeito que tem que ser...como fica bom pra mim e como fica bom pra eles [filhos], né?" (M3-E); “Ai...é rara! [a participação do pai na vida do filho] (...). Eu até por um lado eu sou egoísta e gosto disso, sabe, eu gosto até. Tem horas que eu cobro isso, tem horas que eu gosto deles não serem tão próximos" (M4-E).

Nesse ensejo, destaca-se também que algumas mães foram categóricas em afirmar que os filhos não sentem falta do pai, sendo indiferentes à sua ausência. Resultados semelhantes foram encontrados no estudo de Reis (2010) que, ao entrevistar pais e mães que possuíam ações judiciais referentes à guarda de filhos ou regulamentação de visitas, identificou que as mães entrevistadas não atribuíam importância à existência ou não de afeto entre pai e filho, considerando que não perguntar pelo pai indicaria que a criança não sente falta dele: "Eu não sei se o João sente a ausência do pai, porque ele não fala, sabe, ele não fala, eu não pergunto, a gente nem toca no pai, no nome do pai. Acho que não morre de amores, não sente falta, não tem necessidade do pai, por que? Nunca teve a presença do pai, né?" (M4-G); "Não, acho que não [se o filho sente falta do pai] ele se acostumou assim ...inclusive ele disse assim pra mim "mãe, eu vou onde tu for, eu faço o que tu me disser pra fazer, ele não... ele não é o que tu é pra mim" [fica emocionada] (M3-E).

Tais considerações fazem pensar se essa falta de verbalização dos filhos a respeito da ausência do pai diz respeito, efetivamente, a uma indiferença dos mesmos em relação a esse distanciamento. Ou, então, se poderia ser atribuída a uma aliança estabelecida entre mãe e filho uma vez que é a mãe que se manteve presente -, o que leva as crianças a tentarem não expressar a falta que lhes faz a presença do pai por receio de magoar essa mãe (Brito, 2007; Wallerstein \& Kelly, 1998).

Diante das questões apresentadas, pôde-se perceber que as mães precisam lançar mão de algumas estratégias para dar conta do impacto da ausência paterna na vida dos filhos. Embora algumas participantes tenham relatado não ver importância na relação entre pai e filho - talvez por entender que a paternidade ocupa um lugar periférico e secundário se comparada à maternidade (Reis, 2010) - outras reconheceram a importância do pai e de que sua ausência gera sofrimento para as crianças.

\section{Considerações Finais}

Diante das narrativas apresentadas, evidenciou-se que muitas retratavam histórias de filhos que não foram planejados, frutos de relações instáveis. Nesse sentido, diversos motivos foram apresentados para justificar a ocorrência da gestação em uma relação não estável, tais como: "descuido", vontade do ex-companheiro em ser pai, desejo em compartilhar o cuidado dos filhos. Porém, pode-se pensar que tais decisões tenham sido motivadas, em certos casos, mais do que por uma deliberação avaliada de ter um 
filho por parte do casal - ou seja, uma decisão parental -, por uma busca, mesmo que não claramente apresentada, de resgate conjugal.

Os aspectos apontados pelas mães envolvendo a relação conjugal e o projeto parental não compartilhado são importantes contribuições no sentido de compreender as implicações desses elementos no exercício da parentalidade e seus desdobramentos na vida dos filhos. Puderam-se identificar posições ambivalentes e singulares por parte das participantes com relação tanto a ausência quanto a um maior envolvimento dos pais na vida dos filhos. Esses achados parecem estar relacionados com as experiências socioculturais dessas mães e também dos aspectos históricos, que atribuíram aos pais um lugar mais distante e periférico no cuidado com os filhos.

Dessa forma, os resultados deste estudo parecem indicar a relevância dos estudos envolvendo a parentalidade, em especial a manutenção da coparentalidade, como uma forma de superar os papeis historicamente definidos para pais e mães na relação de cuidado com os filhos. Os resultados deste estudo parecem sustentar ainda, a relevância da modalidade de guarda compartilhada, recentemente adotada no sistema jurídico brasileiro, justamente porque essa modalidade tem, em seu principal pressuposto, a busca pela manutenção da coparentalidade dos pais nas famílias pós-divórcio.

Salienta-se, por fim, a importância de que mais estudos que contemplem a dinâmica familiar, enfocando a dissolução do relacionamento conjugal e seus desdobramentos, devam ser realizados, com vista a uma maior compreensão dos aspectos que envolvem as relações familiares no contexto atual. Como limitações do estudo, pode-se demarcar o fato de os dados referentes à gestação serem retrospectivos. Além disso, salienta-se que o estudo foi realizado com uma determinada população de mães, as quais compõem um determinado grupo sociocultural, não sendo representativas de todas as mulheres, e também o fato de que o estudo teve como participantes apenas mulheres. Nesse sentido, sugere-se que estudos futuros possam ser realizados incluindo outros grupos sociais e também outros membros da família.

\section{Referências}

Barbour, R. (2009). Grupos focais. Porto Alegre: Artmed.

Bardin, L. (2011). Análise de conteúdo (Ed. rev. e amp.; L. A. Reto \& A. Pinheiro, Trad.). Lisboa: Edições 70.

Borsa, J. C., Nunes, M. L. T. (2011). Aspectos psicossociais da parentalidade: $\mathrm{O}$ papel de homens e mulheres na família nuclear. Psicologia Argumento, 26(64), 31-30.

Brasil. (2012). Ministério da Saúde. Resolução 466/12 - Diretrizes e Normas Regulamentadoras de Pesquisas envolvendo Seres Humanos. Brasília-DF.

Brito, L. M. T. (2007). Família pós-divórcio: A visão dos filhos. Psicologia: Ciência e Profissão, 27(1), 32-45. doi: 10.1590/ S1414-98932007000100004.

Castillo, J. T. (2010). The relationship between non-resident fathers' social networks and social capital and the establishment of paternity. Child and Adolescent Social Work Journal, 27(3), 193-211.
Corso, D. L., \& Corso, M. (2011). A psicanálise na terra do nunca: Ensaios sobre a fantasia. Porto Alegre: Penso.

Creswell, J. W. (2010). Projeto de pesquisa: Métodos qualitativo, quantitativo e misto. Porto Alegre: Artmed.

Cúnico, S. D., \& Arpini, D. M. (2013). O afastamento paterno após o fim do relacionamento amoroso: Um estudo qualitativo. Interação em Psicologia, 17(1), 99-108. doi: 10.5380/psi. v17i1.27560

Dantas, C., Jablonski, B., \& Féres-Carneiro, T. (2004). Paternidade: Considerações sobre a relação pais-filhos após a separação conjugal. Paidéia, 14(29), 347-357. doi: 10.1590/S0103863 X2004000300010.

Dolto, F. (2011). Quando os pais se separam (V. Ribeiro, Trad.). Rio de Janeiro: Zahar. (Original publicado em 1989)

East, L., Jackson, D., \& O'Brien, L. (2006). Father absence and adolescent development: A review of the literature. Journal of Child Health Care, 10(4), 283-295.

Eizirik, M., \& Bergmann, D. S. (2004). Ausência paterna e sua repercussão no desenvolvimento da criança e do adolescente: Um relato de caso. Revista de Psiquiatria do Rio Grande do Sul, 26(3), 330-336. doi: 10.1590/S0101-81082004000300010.

Ferrari, J. L. (2007). Ser padres en el tercer milênio. Mendoza: Editorial del Canto Rodado.

Fonseca, C. (2005). Paternidade brasileira na era do DNA: A certeza que pariu a dúvida. Cuadernos de Antropologia Social, 22, $27-51$.

Gaskell, G. (2005). Entrevistas individuais e grupais. In M. Bauer \& G. Gaskell (Orgs.), Pesquisa qualitativa com texto, imagem e som (pp. 64-89). Petrópolis, RJ: Vozes.

Gil, A. C. (2002). Como elaborar projetos de pesquisa. São Paulo: Atlas.

Gomes, A. J. S., \& Resende, V. R. (2004). O pai presente: O desvelar da paternidade em uma família contemporânea. Psicologia: Teoria e Pesquisa, 20(2), 119-125. doi: 10.1590/S010237722004000200004.

Grzybowski, L. S., \& Wagner, A. (2010). Casa do pai, casa da mãe: A coparentalidade após o divórcio. Psicologia: Teoria e Pesquisa, 26(1), 77-87. doi: 10.1590/S0102-37722010000100010.

Hack, S. M. P. K., \& Ramires, V. R. R. (2010). Adolescência e divórcio parental: Continuidades e rupturas dos relacionamentos. Psicologia Clínica, 12(1), 85-97. doi: 10.1590/S010356652010000100006

Housel, D. 2004. As implicações da parentalidade. In M. C. P. Silva, \& L. Solis-Ponton (Orgs.), Ser pai, ser mãe. Parentalidade: Um desafio para o terceiro milênio (pp. 47-51). São Paulo: Casa do Psicólogo.

King, V., \& Heard, H. (1999). Nonresident father visitation, parental conflict, and mother's satisfaction: What's best for child wellbeing? Journal of Marriage and the Family, 61(2), 385-396.

Lopes, R. C. S., Menezes, C., Santos, G. P. dos, \& Piccinini, C. A. (2006). Ritual de casamento e planejamento do primeiro filho. Psicologia em Estudo, 11(1), 55-61. doi: 10.1590/S141373722006000100007.

Matias, M., Silva, A., \& Fontaine, A. M. (2011). Conciliação de papéis e parentalidade: Efeitos de género e estatuto parental. Exedra, 5, 57-76. 
Padilha, C. C. (2008). Quando o pai vira réu por alegação de abandono afetivo. In L. M. T. Brito (Org.), Famílias e Separações: Perspectivas da Psicologia Jurídica (pp. 187217). Rio de Janeiro: ED/UERJ.

Pereira, R. C. (2011). Divórcio - Teoria e prática. Rio de Janeiro: GZ.

Pereira, C. R. R., \& Arpini, D. M. (2012). Os irmãos nas novas configurações familiares. Psicologia Argumento, 30(69), 275-285.

Pittman, F. (1994). Mentiras privadas: A infidelidade e a traição da intimidade. Porto Alegre: Artes Médicas.

Prietsch, S. O. M., González-Chica, D. A., Cesar, J. A., \& MendozaSassi, R. A. (2011). Gravidez não planejada no extremo Sul do Brasil: Prevalência e fatores associados. Cadernos de Saúde Pública, 27(10), 1906-1916. doi: 10.1590/S0102311X2011001000004

Reis, E. F. (2010). Varas de família - Um encontro entre Psicologia e Direito. Curitiba: Juruá.

Sganzerla, I. M., \& Levandowski, D. C. (2010). Ausência paterna e suas repercussões para o adolescente: Análise da literatura. Psicologia em Revista, 16(2), 295-309.

Spengler, F. M. (2012). O fim das relações amorosas: Como mediar o litígio para ter uma convivência pacífica após a separação? In D. S. Ibias (Org.), Família e seus desafios: Reflexões pessoais e patrimoniais. (pp. 243-250). Porto Alegre: IBDFAM/RS.
Staudt, A. C. P., \& Wagner, A. (2008). Paternidade em tempos de mudança. Psicologia: Teoria e Prática, 10(1), 174-185.

Szejer, M., \& Stewart, R. (1997). Nove meses na vida da mulher. São Paulo: Casa do Psicólogo.

Tachibana, M., Santos, L. P., \& Duarte, C. A. M. (2006). O conflito entre o consciente e o inconsciente na gravidez não planejada. Psychê, 19, 149-167.

Turatto, E. R. (2008). Tratado de metodologia da pesquisa clínicoqualitativa. Petrópolis: Vozes.

Turney, L. (2011). The denial of paternity: Pregnancy as a risk to the 'pure relationship'. Sociology, 45(6), 1110-1125.

Veludo, C. M, B, \& Viana, T, De C. (2012). Parentalidade e o desenvolvimento psíquico na criança. Paidéia, 22(51), 111118. doi: 10.1590/S0103-863X2012000100013

Wallerstein, J., \& Kelly, J. (1998). Sobrevivendo à separação: Como pais e filhos lidam com o divórcio (M. A. V. Veronese, Trad.). Porto Alegre: Artmed.

Warpechowski, A., \& Mosmann, C. (2012). A experiência da paternidade frente à separação conjugal: Sentimentos e percepções. Temas em Psicologia, 20(1), 247-260.

Recebido em 05.08.2014

Primeira decisão editorial em 26.06.2016

Versão final em 12.08.2016

Aceito em 12.08.2016 